Sebastian Marian Zaharia

Camil Lancea

Lucia Antoneta Chicos

Mihai Alin Pop

Giampaolo Caputo

Emanuele Serra

https://doi.org/10.21278/TOF.41402

ISSN 1333-1124

eISSN 1849-1391

\title{
MECHANICAL PROPERTIES AND CORROSION BEHAVIOUR OF 316L STAINLESS STEEL HONEYCOMB CELLULAR CORES MANUFACTURED BY SELECTIVE LASER MELTING
}

\begin{abstract}
Summary
Selective laser technology is an additive technology that can allow for the manufacture of cellular structures using different types of metallic powder with complex applications in industries such as aerospace, automotive and medical implant industries. This paper presents the effect of climate and mechanical stresses on some honeycomb cellular cores, used in sandwich structures made of $316 \mathrm{~L}$ stainless steel powder by applying the selective laser melting technology. The honeycomb cellular cores have undergone the microhardness testing and the resulting variation obtained from the analyzed samples was $225 \pm 15 \mathrm{HV}_{0.3}$. The compressive strength and the modulus of elasticity of the cellular structures were determined for flatwise and edgewise compressive stresses. Also, the cellular structures were subjected to accelerated corrosion tests in order to determine their mean life in application use conditions similar to those near seas and oceans. Also, a microstructural evaluation of salt deposits was carried out on the cellular structures subjected to accelerated corrosion tests using a salt spray test chamber.
\end{abstract}

Key words: $\quad$ selective laser melting, honeycomb cellular core, 316 L stainless steel, mechanical performance, accelerated corrosion test

\section{Introduction}

The development and manufacture of sandwich structures already successfully used in areas such as aerospace industry (structures of helicopter blades, fuselage floors, empennage structures), automotive industry (inside panels), renewable energy industry (blades of wind turbines), marine industry (flooring, hull, bulkheads), railway industry (construction of highspeed trains, wagons), packaging industry (corrugated cardboard), construction industry (sandwich panels used to build facades, roofs) have been extensively investigated and presented [1]. The sandwich structure has a low density core which takes over the 
compressive and shear stresses. Between two shells the following core structures can be inserted: wood, honeycomb structure (paper, aluminium alloys, titanium and copper alloys, nickel alloys, iron alloys, fiber glass, carbon fibers, kevlar) and expanded foam [2]. The most frequently used metal cores are honeycomb core structures. They are cellular structures that are used in particular in the production of airplane floors, leading and trailing edges in wings, fuselage components, and helicopter rotor blades. Special attention is given to the environmental protection; for this purpose, the land, sea and air vehicles must be more efficient in terms of fuel consumption and take the so-called "lightweight syndrome" into account. This syndrome refers to obtaining lighter sandwich structures which reduce the weight of various components while increasing their performances. Light metal cellular structures have high strength, a relatively low weight and good performances related to: energy absorption and thermal and acoustic insulation.

One modern method of manufacturing cellular structures used in sandwich structures is the additive technology. By using the additive technology the three-dimensional models of complex shapes can be achieved starting from digital three-dimensional parts by adding successive layers of material in a few hours, with minimal intervention of the human factor [3]. The main advantages of the additive manufacturing technologies are: reduction in cost of the new product; the application of these technologies allows for the experimentation with constructive solutions for the designed technological equipment, its validation or improvement; carrying out tests on models produced by the additive manufacturing technology [4]. The main types of additive manufacturing technologies are [5]: stereolithography (SLA); fused deposition modelling (FDM); selective laser sintering (SLS); selective laser melting (SLM); electronic beam melting (EBM); laminated object manufacturing (LOM). In the framework of this study the laser melting technology will be used to obtain multilayer cellular structures by consolidating some successive layers of powder type material and by using a laser in order to melt and solidify the required geometry starting from a three-dimensional model. The SLM technology allows for the manufacture of cellular structures or components using a wide range of materials: pure titanium [6], titanium alloy [7,8,9], cobalt-chrome [10,11], stainless steel [12,13] and aluminum alloy $[14,15,16]$.

Recent studies on cellular structures manufactured by the SLM technology can be divided into the following main areas of interest: optimizing the laser settings (power and exposure time) in order to obtain different structures and the effect of production parameters in stainless steel [17]; manufacture of implants using cellular structures [18,19], manufacture and optimization of cellular structures geometry produced by the SLM technology, starting from the unit cell geometries, sizes and strut cell diameters [20,21,22,23], testing the cellular structures obtained by the SLM technology [9,14,15,22,23], finite element analysis of cellular structures [17,24].

A great part of the studies on cellular structures focus on the manufacture and then the determination of the failure and deformation mechanisms followed by various microscopic analyses. The behaviour testing analysis of cellular structures manufactured by using the additive technology is a challenge for specialists in the field. Tests are currently performed to determine the mechanical properties of cellular structures under various stresses (compressive, bending and tensile), that are obtained by the SLM technologies. Mines et al. [25] studied the impact behaviour of sandwich panels with carbon fibre reinforced polymer (CFRP) face sheets and micro lattice core (body centered cubic /BCC/) of the Ti6Al4V and the 316L stainless steel manufactured by the SLM technology. Another study was undertaken by Riemer et al. [26] who investigated the high-cycle fatigue performance of 316L steel 
Mechanical Properties and Corrosion Behaviour of 316L Stainless Steel Honeycomb Cellular Cores Manufactured by Selective Laser Melting
S.M. Zaharia, C. Lancea, L.A. Chicos, M.A. Pop, G. Caputo, E. Serra

cellular structures, focusing on the study of crack initiation and growth behaviour occurred as a result of the testing. Smith et al. [24] used experimental methods for determining the compressive response of several $\mathrm{BCC}$ and $\mathrm{BCC}-\mathrm{Z}$ cellular structures and validated the experimental results by applying the finite element method.

Various analytical methods, experimental and numerical were used by Ushijima et al. to determine the mechanical properties of BCC micro-cellular structures under uniaxial [27,28] and multiaxial compression [29]. McKeown et al. [30] produced two types of cellular structures: the pillar-octahedral lattice and the octahedral lattice using the SLM technology and studied the compression and the blast behaviour. Microstructure, high cycle fatigue and failure mode of 91 specimens made of the AlSi10Mg aluminium alloy by using the SLM technology, in three building directions $\left(0^{\circ}, 45^{\circ}, 90^{\circ}\right)$ were investigated by Brandl et al. [14]. A manufacturing process was developed and performance of gyroid structures (with different volume fractions) under compressive strength was analyzed by Yan et al. [21]. Zhang et al. [31] studied the influence of the manufacturing process parameters (laser beam scanning velocity, laser power, substrate condition and thickness of the powder layer) of stainless steel $316 \mathrm{~L}$ specimens (positioned horizontally and vertically on the machine table) in order to improve the mechanical performance and their dimensional accuracy using the SLM 250 device. Recent studies on the determination of the Brinell hardness of the structures made of 316L stainless steel components and manufactured by SLM were carried out by Buican et al. [32] and by Zhu et al. [33]. The specimens manufactured by the SLM technology were investigated in terms of their corrosion behaviour and resistance by carrying out electrochemical measurements to $3.5 \mathrm{wt} . \% \mathrm{NaCl}$ [34]. Alsalla et al. [35] studied the effect of different building directions on the properties of density, tensility and fracture toughness of 316L stainless steel cellular lattice structures manufactured by the SLM technology. Prashanth et al. [36] investigated the compression behaviour of different specimen geometries from the open-cell rhombi-dodecahedron structure with three different density values and fabricated from the $316 \mathrm{~L}$ gas-atomized powder using the selective laser melting. Another recent study was performed by Feng et al. [37] including the theoretical method and the finite element analysis for predicting mechanical properties of BCC structures and uniaxialreinforced BCCZ and $\mathrm{A} 2 \mathrm{BCC}$ structures manufactured by using the SLM technology. Martin et al. [38] used a modified ceramic extrusion powder technology and analyzed mechanical properties and energy absorption efficiency of the honeycomb design based on austenitic stainless TRIP-steel and TRIP-steel/zirconia composite (TRIP-MC) materials.

Stainless steel honeycomb structures used in aviation are analyzed and tested for corrosion because the number of aircraft kept in operation is increasing. One of the most important causes of damage to aircraft is the corrosion of metallic components (in this paper we study the cellular honeycomb core) affected by sand, rain or an environmental pollutant with a high content of salts, acids and alkalis. The prevention, mitigation and monitoring of the cellular honeycomb core's corrosion is a common concern to companies in the aerospace industry. In the current scientific context in which in the coming years large companies in the aerospace, road, sea, rail transport and renewable energy sector want to achieve industrial products (aircraft, racing cars, trains, blades for wind turbines) with at least $50 \%$ functional components made by additive technology, manufacturing, and the testing of such cellular structures represents a vast and extensively researched field of study.

The objective of this study is to determine the mechanical behaviour of the honeycomb cellular core in sandwich structures produced by the laser melting technology. The first experimental stage was the mechanical characterization of the cellular core structures 
obtained by microhardness testing. This paper will expand the experimental research, present above and will determine the compressive performance of honeycomb core type cellular structures made of the 316L stainless steel and manufactured by applying the SLM technology. A particular attention is given to the accelerated corrosion testing of core cellular type structures in order to determine the mean life and weight loss over a long period of time. Additionally, on the cellular core structures subjected to accelerated corrosion tests, a microstructural characterization was performed by using electron scan microscopy.

\section{Materials and methods}

\subsection{Material and honeycomb cellular cores preparation}

The honeycomb cellular core have been modelled in the SolidWorks software and then exported in the stl. format. For their manufacture the SLM 250 HL equipment from SLM Solutions was used. To generate data on the manufacturing process of SLM, the SLM AutoFab software (Marcam Engineering $\mathrm{GmbH}$ ) was used. The cellular core type structures were manufactured by depositing several thin layers of atomized stainless steel metal powder (316L stainless steel), which successively melted and solidified at the microscopic level inside a closed building chamber containing the inert gas argon. The manufacturing process was carried out at SLM Solutions Company from Luebeck, Germany.

$316 \mathrm{~L}$ stainless steel powder used for the honeycomb cellular core structures has the following composition: $\mathrm{C} \leq 0.03 \%$; $\leq 2.0 \% \mathrm{Mn} ; \mathrm{Si} \leq 0.75 ; \approx 12 \%-14 \% \mathrm{Ni} ; \mathrm{Cr} \approx 16 \%-18 \%$; $\mathrm{Mo} \approx 2 \%-3 \% ; \mathrm{S} \leq 0.03 ; \mathrm{P} \leq 0.045 ; \mathrm{Fe}$ balance. In the experiments of this study, the following parameters were applied:

Table 1 Manufacturing parameters of the honeycomb cellular cores

\begin{tabular}{|l|l|}
\hline Parameters & Value \\
\hline Laser power & $100 \mathrm{~W}$ \\
\hline Layer thickness & $50 \mu \mathrm{m}$ \\
\hline Laser scanning speed & $150 \mathrm{~mm} / \mathrm{s}$ \\
\hline Hatch offset & $0.175 \mathrm{~mm}$ \\
\hline Particle size & $20-40 \mu \mathrm{m}$ \\
\hline Platform temperature & $200^{\circ} \mathrm{C}$ \\
\hline Inert gas, Argon & $4.6 \mathrm{bar}, 2 \mathrm{lmin}$ \\
\hline
\end{tabular}

For the purpose of this study, 20 cellular core structures made of $316 \mathrm{~L}$ stainless steel were manufactured. The honeycomb specimens of the cellular core structures are hexagonal (Fig. 1.a) and have the following dimensions: length $70 \mathrm{~mm}$, width $50 \mathrm{~mm}$, height $12 \mathrm{~mm}$. The specific dimensional elements of a honeycomb core are described in Fig. 1.b. Thus, the cell diameter (d) defined as the distance between two opposite walls of the honeycomb core has a value of $14 \mathrm{~mm}$; the length (a) of an edge of the hexagonal core is $8 \mathrm{~mm}$ with a wall thickness of $1.5 \mathrm{~mm}$. 

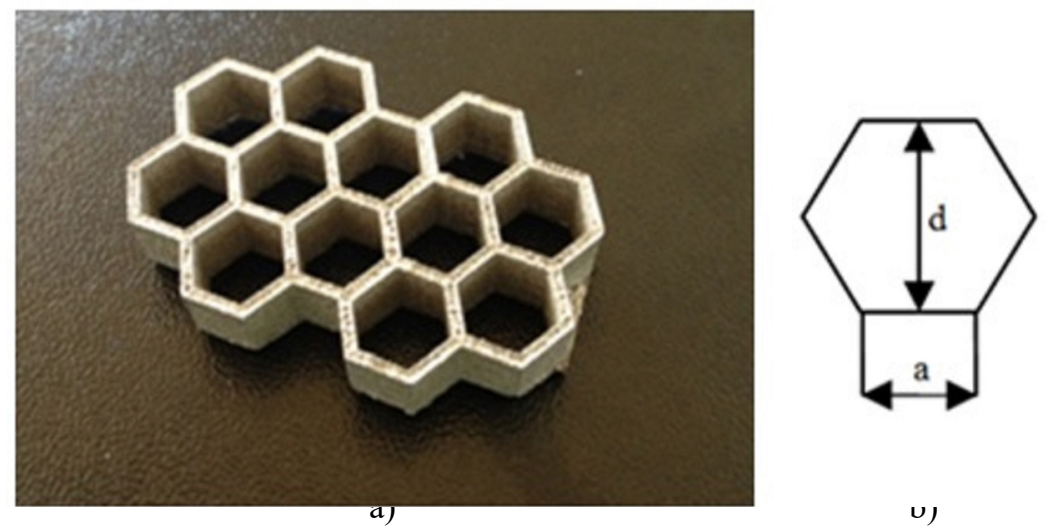

Fig. 1 (a) Honeycomb cellular core structures manufactured by SLM and made of 316L stainless steel, (b) unit cell of a hexagonal honeycomb

\subsection{Experimental methods}

In this study, three kinds of tests were carried out in relation to the honeycomb cellular core structures: microhardness tests, compression tests and accelerated corrosion tests. In determining the microhardness values of the honeycomb cellular cores the Vickers method, based on measuring the size of the field diagonal obtained by indenting a diamond pyramid in the grains of the analyzed material at light loads, was used.

When microhardness of the cellular core structures was tested, the specimens were cut transversely, embedded in epoxy resin and then ground with sandpaper by gradual changing of the grain $(1500,2000$ and 2500) using a Buehler Phoenix Beta - grinder/polisher. It is very important that the cut pieces exhibit a smooth surface and no traces after the cutting operation because these imperfections can influence the values and the accuracy of microhardness tests. The determination of the microhardness was conducted with a FM-700 Microhardness Tester; the penetrator was applied for 15 seconds using a load of $300 \mathrm{gf}$.

Honeycomb cores of a sandwich structure composition are found in many applications in the aerospace sector and the main stresses that occur in these structures are linked to compression. Five structures of honeycomb core type made of $316 \mathrm{~L}$ stainless steel manufactured by SLM underwent the compression testing using a WDW-150S universal testing machine.

All the compression tests were carried out under displacement control at a constant cross-head speed of $2 \mathrm{~mm} / \mathrm{min}$. The dimensions of the honeycomb core type structures compression tested in this paper were manufactured so as to comply with ASTM C365 Standard Test Method for Flatwise Compressive Properties of Sandwich Cores. Five other honeycomb core type structures were edge compression tested. These specimens manufactured by SLM and made of stainless steel have the dimensions from ASTM C364 Standard Test Method for Edgewise Compressive Strength of Sandwich Constructions.

The main cause of sandwich structures deterioration and in particular of honeycomb cores is corrosion, which deserves special attention. These cellular core structures are subjected to fatigue during operation, are affected by various objects, or by the environment they operate in, which becomes increasingly polluting (due to a high content of salts). The honeycomb cores made of $316 \mathrm{~L}$ stainless steel and manufactured by SLM were subjected to accelerated corrosion tests. The accelerated corrosion tests were conducted in salt spray chamber of the laboratory of the Italian National Agency for New Technologies, Energy and 
Sustainable Economic Development. Before starting the corrosion test on the honeycomb cores the guidelines of ISO 9227, Corrosion Tests in Artificial Atmospheres - Salt Spray Test, were extensively looked into, as they contain very useful recommendations on the preparation of specimens for the testing.

Since SLM technologies are new, many aspects concerning material performance data are unknown. Due to the long periods of testing necessary to obtain information on cellular core structures, the implementation of accelerated corrosion tests is clearly required. By using these types of accelerated tests on materials produced by the SLM technology the corrosion behaviour can be anticipated, the testing costs are thus reduced and the reliability is improved.

The main research aspects of performing the accelerated corrosion salt spray tests on honeycomb cores manufactured by SLM are the prediction of the mean life of the structures and the weight loss. Two sets of tests were performed for each 5 specimens that were subjected to $5 \% \mathrm{NaCl}$ (sodium chloride) and $10 \% \mathrm{NaCl}$ with an exposure time of 240 hours. At the end of the accelerated corrosion salt spray tests, the honeycomb cores were analyzed in terms of salt deposits by using a LEO 1525 field emission scanning electron microscope.

\section{Results and discussions}

\subsection{Microhardness test}

The Vickers method is well suited for microhardness testing of thin pieces or pieces with thin superficial layers of small thickness, the load applied in these cases becoming increasingly smaller, depending on the layer thickness. For the microhardness testing three samples were collected from the honeycomb core structures manufactured by SLM in order to determine their microhardness characteristics. Table 2 describes the microhardness test results.

Table 2 Values of microhardness samples

\begin{tabular}{|c|c|c|c|}
\hline No. & $\begin{array}{c}\text { Microhardness sample 1 } \\
\mathrm{HV}_{0.3}\end{array}$ & $\begin{array}{c}\text { Microhardness sample 2 } \\
\mathrm{HV}_{0.3}\end{array}$ & $\begin{array}{c}\text { Microhardness sample 3 } \\
\mathrm{HV}_{0.3}\end{array}$ \\
\hline 1. & 218.90 & 220.30 & 223.80 \\
\hline 2. & 216.80 & 213.50 & 235.80 \\
\hline 3. & 216.90 & 209.60 & 231.00 \\
\hline 4. & 231.00 & 234.50 & 226.00 \\
\hline 5. & 228.50 & 234.50 & 216.00 \\
\hline 6. & 210.50 & 217.50 & 227.00 \\
\hline 7. & 232.50 & 226.50 & 218.00 \\
\hline 8. & 224.50 & 231.40 & 214.00 \\
\hline 9. & 236.50 & 228.00 & 237.00 \\
\hline 10. & 235.60 & 225.00 & 234.00 \\
\hline
\end{tabular}

Analyzing the results obtained from the microhardness tests using the SPSS Statistics 23 software the following values, described by the frequency distributions, have been obtained (Fig. 2). Since the mean, the median and the mode value are relatively equal in the three tested samples, the distribution is considered to be normal with a slight positive asymmetry. After determining the microhardness of the $316 \mathrm{~L}$ stainless steel samples by averaging the ten microhardness values (Fig. 3) obtained from the surface of the sample, a mean of $225.4 \mathrm{HV}_{0.3}$ microhardness is obtained. In Figure 3 it can be observed that much of the microhardness values of the samples is contained in the rectangle described by the 25 th percentile and the 75 th percentile. 
Mechanical Properties and Corrosion Behaviour of 316L Stainless Steel Honeycomb Cellular Cores Manufactured by Selective Laser Melting

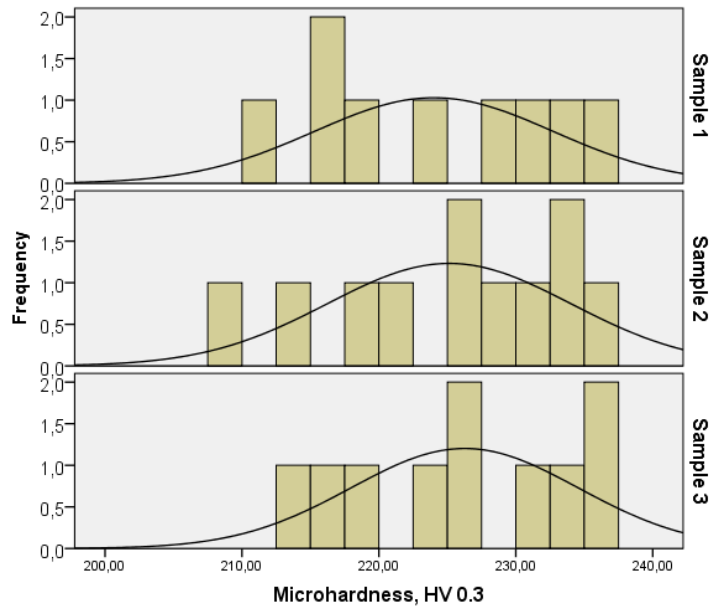

Fig. 2 Histograms of three samples tested for microhardness
S.M. Zaharia, C. Lancea, L.A. Chicos, M.A. Pop, G. Caputo, E. Serra

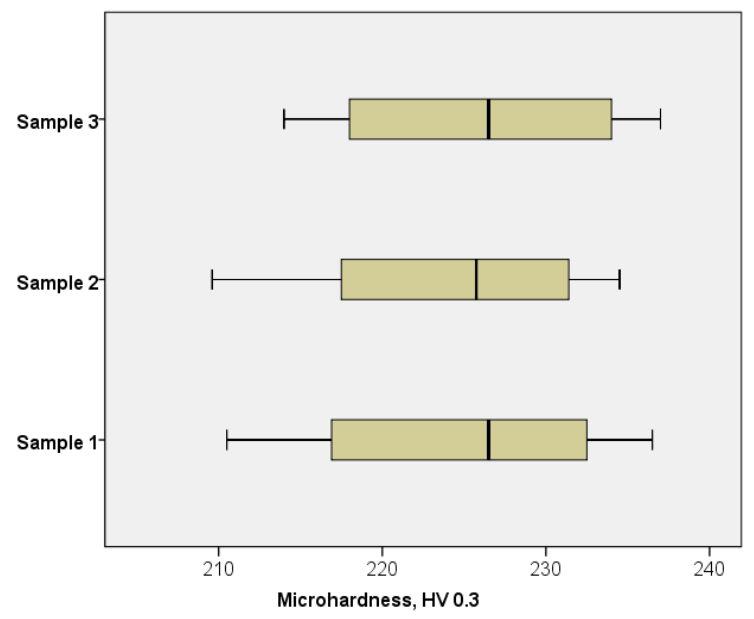

Fig. 3 Box type graph showing microhardness values of three tested samples

\subsection{Compressive testing of honeycomb cellular cores}

For the structural evaluation of the sandwich core structures performances a wide range of tests can be carried out: moisture sorption; compressive testing; shear tests; tensile testing; water migration; delamination of honeycomb core. In this paper, five honeycomb cores will be tested with regard to edgewise compression (Fig. 4) and flatwise compression (Fig. 5). The purpose of these tests is to determine the compressive properties of the honeycomb cores of $70 \mathrm{~mm}$ x $50 \mathrm{~mm}$ size manufactured by SLM technology and made of 316L stainless steel.

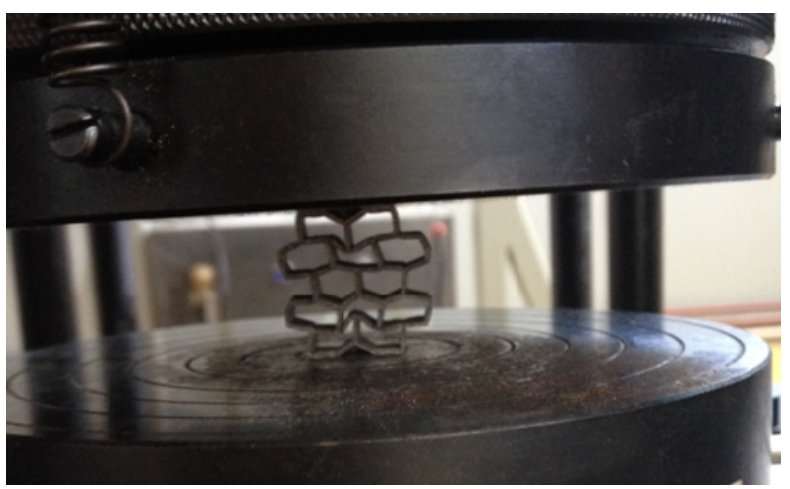

Fig. 4 Testing the edgewise compression of honeycomb cellular cores

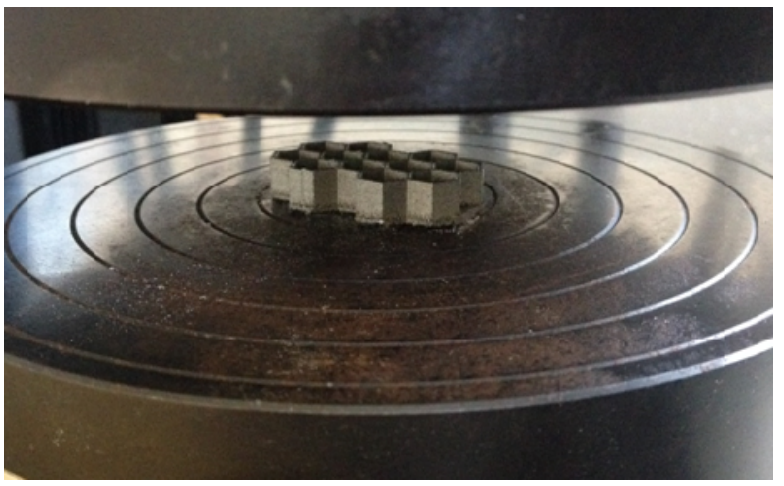

Fig. 5 Testing the flatwise compression of honeycomb cellular cores

With a complete load extension curve it is possible to determine the core compressive strength and the modulus of elasticity of the honeycomb core structure. In Figure 6 it can be seen that the value of the modulus of elasticity of the five flatwise compression tested samples is 22 times higher than the modulus of elasticity of the five edgewise compression tested samples. Another characteristic of the compression tests is the compressive strength of the cellular core structures. The compressive strength values of the ten tested samples are shown in Figure 7. Typically, these compression tests results show that the samples subjected to flatwise compression have a 15 times higher compressive strength when compared with those subjected to edgewise compression. 
S.M. Zaharia, C. Lancea, L.A. Chicos, M.A. Pop, G. Caputo, E. Serra

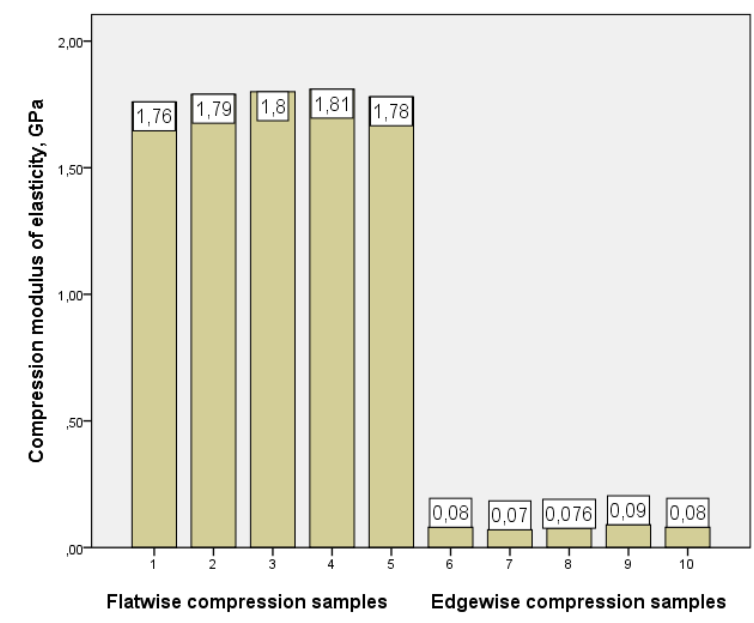

Fig. 6 Flatwise/edgewise compressive modulus of elasticity
Mechanical Properties and Corrosion Behaviour of 316L Stainless Steel Honeycomb Cellular Cores Manufactured by Selective Laser Melting

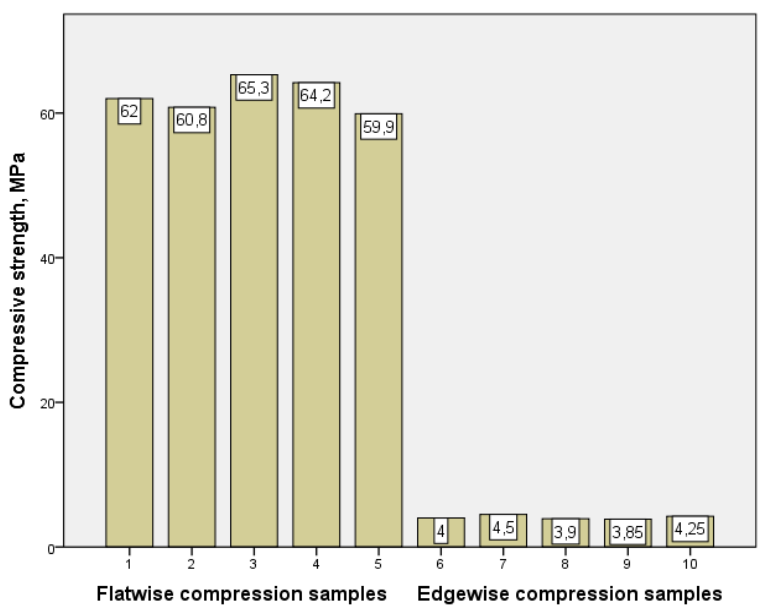

Fig. 7 Flatwise/edgewise compressive strength

The mechanical properties and behaviour of the tested cellular core structures depends on the type of material from which the honeycomb structure is made, and whether deformation occurs in the flatwise or edgewise compression.

In the graphical representation of the compressive strength of the material the characteristic stress-strain curve is used. It is noted that in the flatwise compression (Fig. 8.a) a straight line is obtained which stands for the continuous response of the material to the applied force, in which case the specific deformations are proportional to the stresses.

As for the edgewise compression behaviour (Fig. 8.b) it is found that there is a zone of proportionality between the specific deformations of the applied force, after which, by exceeding the yield point, the characteristic curve shows a hardening zone, and the increase in the deformation in this zone is linked to the increase in the tensile stress. When the maximum level is reached, the pressing down phenomenon of the cellular core structures occurs and the characteristic curve has a downward path until a complete cell core fracture.

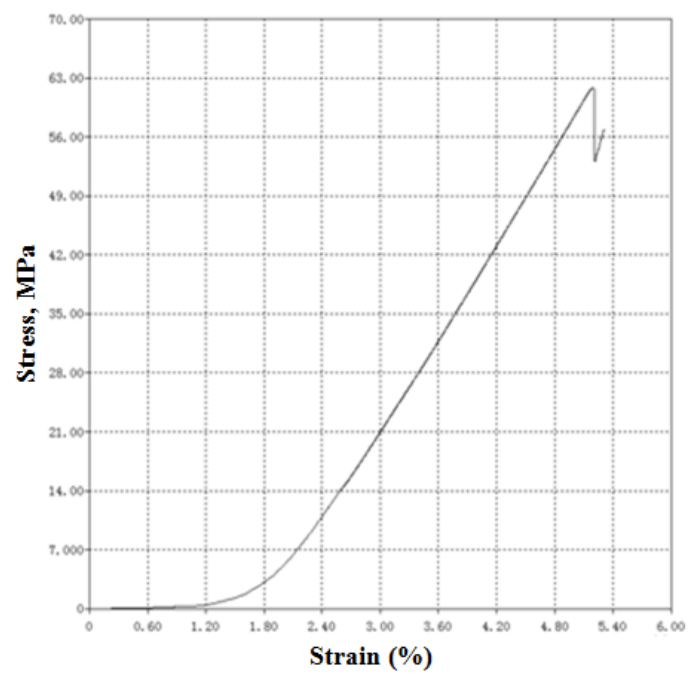

Fig. 8 Stress-strain curve for flatwise compression

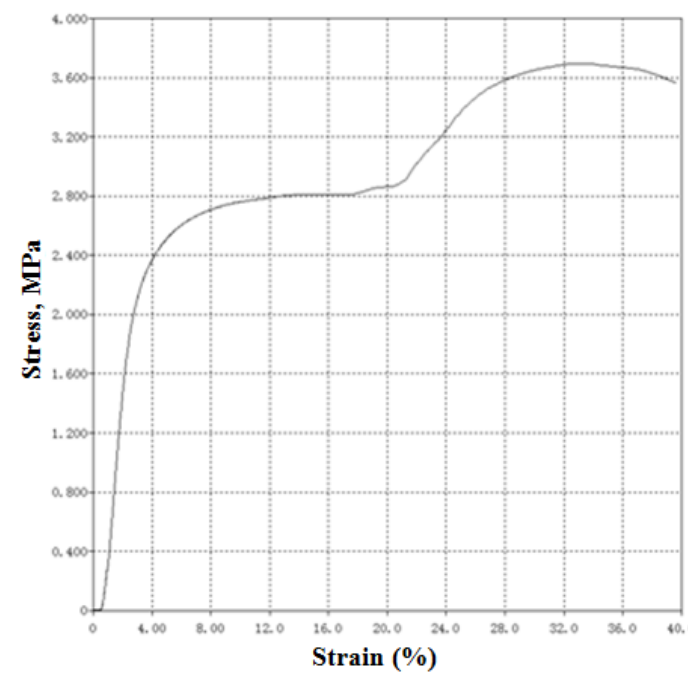

Fig. 9 Stres-strain curve for edgewise compression

The fracture surfaces of the failed $316 \mathrm{~L}$ stainless steel honeycomb cellular cores (subjected to the edgewise compressive tests) were characterized by using a Nikon Eclipse MA-100 optical microscope. As can be seen in Figure 10.a showing the results of the 
Mechanical Properties and Corrosion Behaviour of 316L Stainless Steel Honeycomb Cellular Cores Manufactured by Selective Laser Melting
S.M. Zaharia, C. Lancea, L.A. Chicos, M.A. Pop, G. Caputo, E. Serra

edgewise compression test, the cellular structure reveals total deformation and two surfaces with cracks. The two cracks occurred in the middle area of the specimen, which caused the breaking of the material.

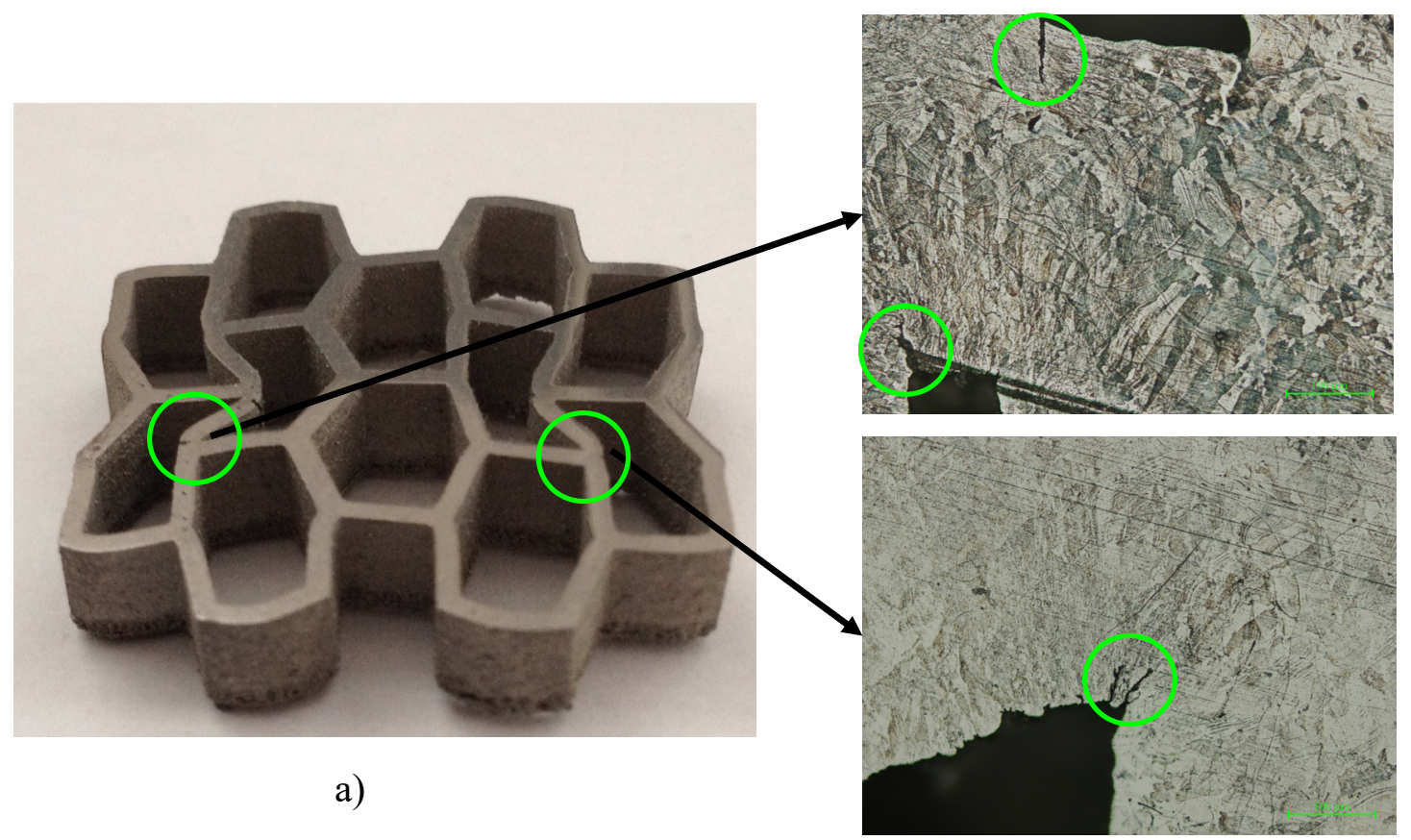

b)

c)

Fig. 10 (a) Fracture surfaces of 316L stainless steel honeycomb cores, (b) Optical microscope images (200X) of specimens subjected to edgewise compression test - the first area with cracks on the specimen,

(c) Optical microscope images (200X) of specimens subjected to edgewise compression test - the second area with cracks on the specimen

\subsection{Accelerated corrosion tests of honeycomb cellular cores}

Mechanisms of the corrosion degradation processes of the cellular core structures under the action of aggressive factors specific to marine environment are an important cause of degradation of components used in various applications. In some metal structures of which a high reliability is estimated, the determination of lifetime in normal stress conditions requires a longer testing time $[39,40]$. For this reason, the accelerated corrosion test methods are selected to carry out the degradation analysis of cellular core structures. Thus, the ten honeycomb cellular cores were exposed to two levels of acceleration with saline solution $(5 \% \mathrm{NaCl}$ and $10 \% \mathrm{NaCl})$ and subsequently analyzed over five exposure times.

Within the process of accelerated corrosion of the cellular core structures the determination was carried out by applying weight loss method. The specimens were extracted from the salt chamber and the corrosion products were removed. These products, removed by cleaning during the inspection, are salts accumulated on the surface of the samples which were removed. In Fig. 9 the weight losses are described in relation to the honeycomb cellular cores surface for the two acceleration levels. 

Manufactured by Selective Laser Melting

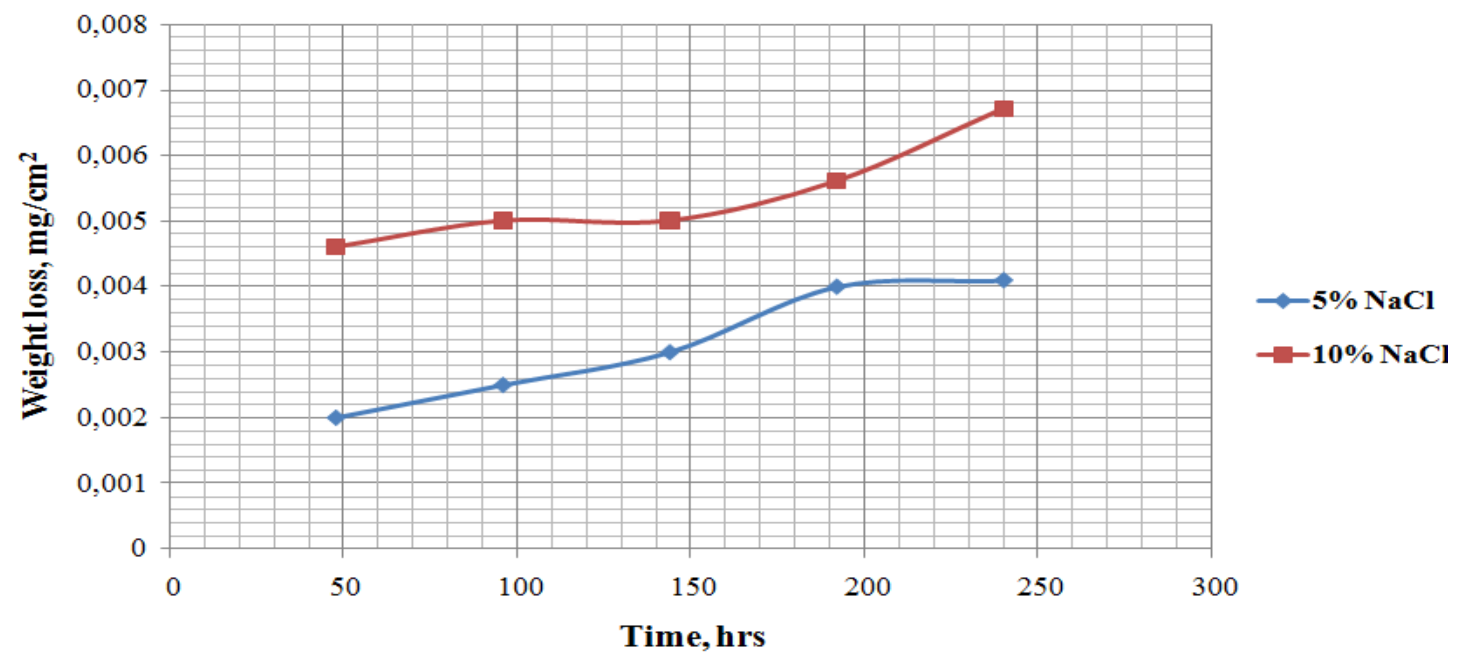

Fig. 11 Variation of mass loss in relation to exposure time of honeycomb cellular cores in two concentrations $(5 \%$ and $10 \%)$ of sodium chloride

For the statistical analysis, the resulting data from the accelerated corrosion tests of the cellular cores was entered into the software ALTA9. The statistical data processing was used as a model for accelerating the Inverse Power Law and the Weibull distribution.

The results obtained from the accelerated corrosion tests were statistically analyzed and then extrapolated so as to obtain the lifetime of cellular core structures under normal use conditions $(0.05 \% \mathrm{NaCl})$. The main indicator determined for these types of accelerated corrosion tests is the mean life. For the cellular core structures, the mean life of 49,638 hours (about five and a half years) in the saturated air near seas and oceans with a normal use of $0,05 \% \mathrm{NaCl}$ was obtained, determined by the Quick Calculation Pad in the software ALTA9.

\subsection{SEM analysis of honeycomb cellular cores}

In Figures 12 and 14 the SEM analysis of the specimens before salt spray testing is presented. The samples tested in the salt chamber $(10 \% \mathrm{NaCl})$ were microstructurally characterized after 96 testing hours using the SEM analysis at $40000 \mathrm{X}$ and $10000 \mathrm{X}$ magnification. It can be observed on the exposed samples that the cell structures show substantial salt deposits (Fig. 13 and Fig 15).

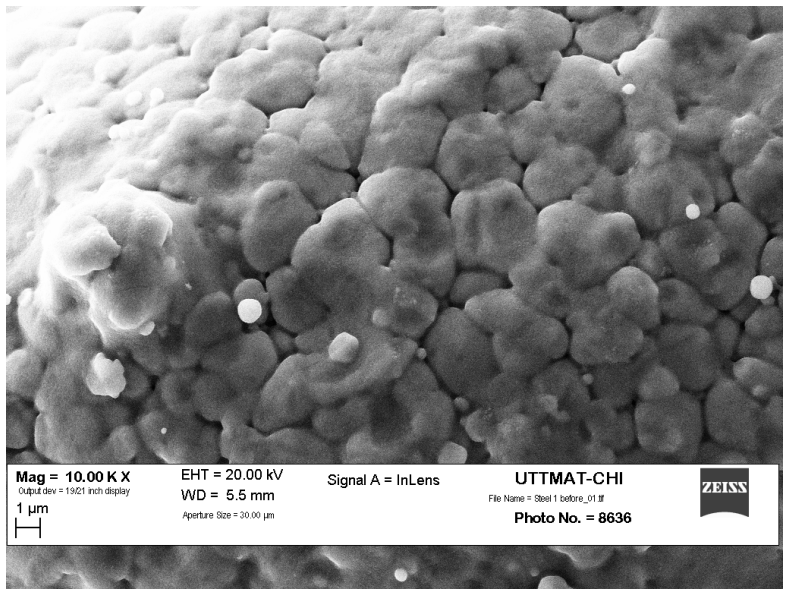

Fig. 12 SEM analysis of samples before exposure in salt spray chamber, magnification: $10.000 \mathrm{X}$

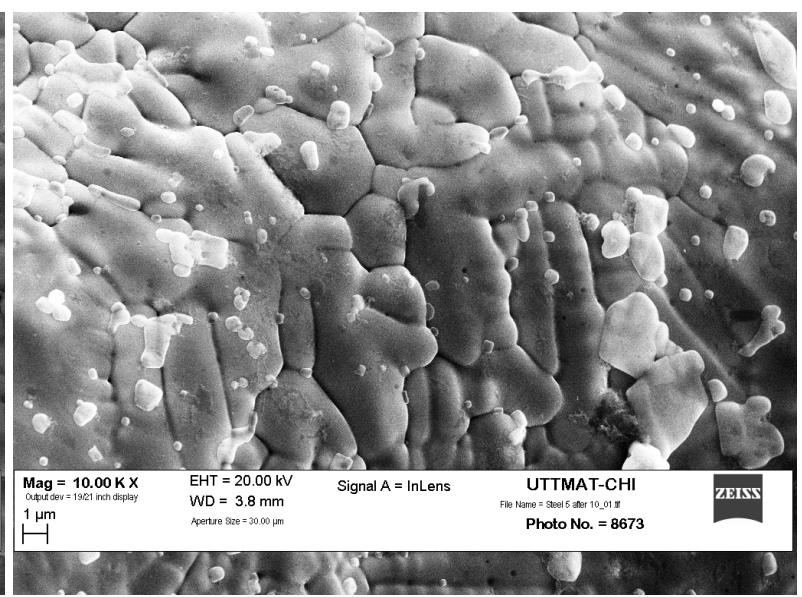

Fig. 13 SEM analysis of samples tested in salt spray chamber, magnification: $10.000 \mathrm{X}$ 
Mechanical Properties and Corrosion Behaviour of 316L Stainless Steel Honeycomb Cellular Cores Manufactured by Selective Laser Melting

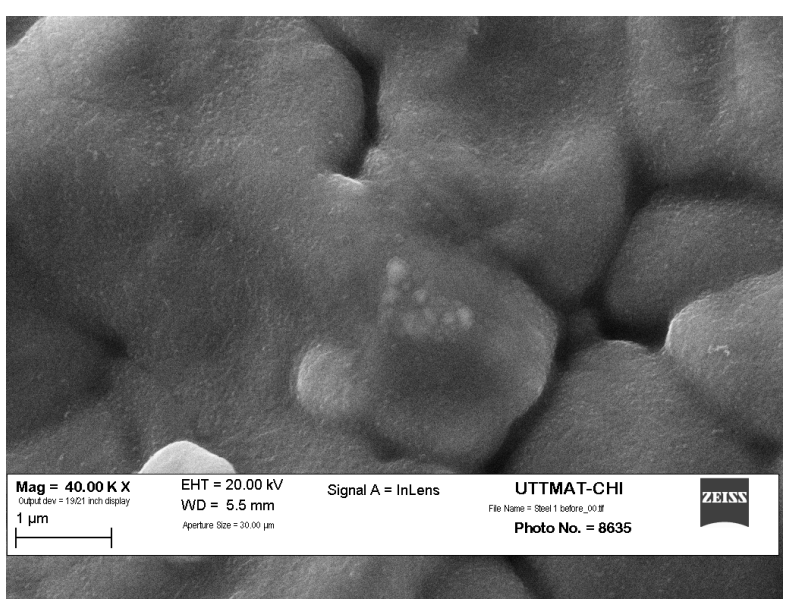

Fig. 14 SEM analysis of samples before exposure in salt spray chamber, magnification: $40.000 \mathrm{X}$
S.M. Zaharia, C. Lancea, L.A. Chicos, M.A. Pop, G. Caputo, E. Serra

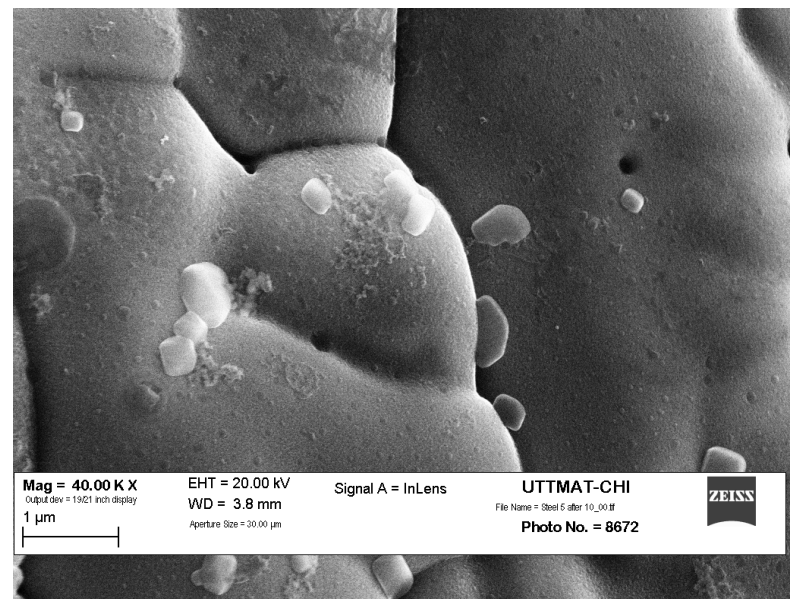

Fig. 15 SEM analysis of samples tested in salt spray chamber, magnification: $40.000 \mathrm{X}$

\section{Conclusions}

The cellular cores manufactured by applying the SLM technology can be implemented in sandwich structures because they exhibit mechanical properties (microhardness and compression) superior to cellular structures obtained by conventional manufacturing technologies. The mean values of microhardness of the three samples analyzed are very close and with the range $\mathrm{HV} 225 \pm 15 \mathrm{HV}_{0.3}$. Upon compression testing it has been observed that the cellular cores have substantially superior performances established by the flatwise compression testing in comparison to those established by the edgewise compression testing.

Within only ten days, the accelerated corrosion tests are capable of producing corrosion equivalent to corrosion observed in five and a half years of normal outdoor use, such as in the marine environment. This reduction in the time of the testing duration and collection of data on cellular core corrosion makes it possible for the accelerated corrosion tests to become an effective method for determination of the corrosion behaviour of materials. After testing the specimens in the salt chamber at two levels of acceleration with saline solution it was concluded that the corrosion rate of specimens increases with an increase in testing duration.

The microscopic analysis of specimens that were subjected to edgewise compression showed the main failure surfaces and how the cracks occurred. The SEM analysis in this paper complements the study on the accelerated corrosion tests by identifying salt deposits on the analyzed cellular structures.

\section{Acknowledgements}

We thank the Structural Funds Project PRO-DD (POS-CCE, O.2.2.1., ID 123, SMIS 2637, and ctr. No 11/2009) for providing the infrastructure used in this study.

Also, the financial support by the Access to Research Infrastructures activity in the 7th Framework Programme of the EU (SFERA Grant Agreement no. 228296) is gratefully acknowledged.

\section{REFERENCES}

[1] F. C. Campbell: Structural Composite Materials. ASM International, 2010.

[2] B. A. Strong: Fundamentals of Composites Manufacturing, Second Edition: Materials, Methods and Applications. Society of Manufacturing Engineers, 2008. 
S.M. Zaharia, C. Lancea, L.A. Chicos, M.A. Pop, G. Caputo, E. Serra
Mechanical Properties and Corrosion Behaviour of 316L Stainless Steel Honeycomb Cellular Cores Manufactured by Selective Laser Melting

[3] I. Gibson, D. Rosen, B. Stucker: Additive Manufacturing Technologies 3D Printing, Rapid Prototyping, and Direct Digital Manufacturing. Springer, 2014.

[4] E. O. Olakanmi, R. F. Cochrane, K.W. Dalgarno: A review on selective laser sintering/melting (SLS/SLM) of aluminium alloy powders: Processing, microstructure, and properties. Progress in Materials Science, 74, 401-477, 2015. https://doi.org/10.1016/j.pmatsci.2015.03.002

[5] P. J. Rousseeuw, A. M. Leroy: Rapid Manufacturing: An Industrial Revolution for the Digital Age. John Wiley \& Sons, 2006.

[6] D. Gu, Y. C. Hagedorn, W. Meiners, G. Meng, R. J. Santos Batista, K. Wissenbach, R. Poprawe: Densification behavior, microstructure evolution, and wear performance of selective laser melting processed commercially pure titanium. Acta Materialia, 60, 9, 3849 - 3860, 2012. https://doi.org/10.1016/j.actamat.2012.04.006

[7] G. Van Bael, Kerckhofs, M. Moesenm, G. Pyka, J. Schrooten, J. P. Kruth: Micro-CT-Based Improvement of Geometrical and Mechanical Controllability of Selective Laser Melted Ti6Al4V Porous Structures. Materials Science and Engineering: A, 528, 24, 7423-7431, 2011. https://doi.org/10.1016/j.msea.2011.06.045

[8] E. Sallica-Leva, A. L. Jardini, J. B. Fogagnolo: Microstructure and Mechanical Behavior of Porous Ti6Al-4V Parts Obtained by Selective Laser Melting. Journal of the Mechanical Behavior of Biomedical Materials, 26, 98-108, 2013. https://doi.org/10.1016/j.jmbbm.2013.05.011

[9] L. Xiao, W. Song, C. Wang, H. Liu, H. Tang, J. Wang: Mechanical behavior of open-cell rhombic dodecahedron Ti-6Al-4V lattice structure. Materials Science and Engineering: A, 640, 375-384, 2015. https://doi.org/10.1016/j.msea.2015.06.018

[10] K. B. Hazlehurst, C. J. Wang, M. Stanford: An investigation into the flexural characteristics of functionally graded cobalt chrome femoral stems manufactured using selective laser melting. Materials \& Design, 60, 177-183, 2014. https://doi.org/10.1016/j.matdes.2014.03.068

[11] K. B. Hazlehurst, C. J. Wang, M. Stanford: A numerical investigation into the influence of the properties of cobalt chrome cellular structures on the load transfer to the periprosthetic femur following total hip arthroplasty. Medical Engineering \& Physics, 36, 4, 458-466, 2014. https://doi.org/10.1016/j.medengphy.2014.02.008

[12] Y. Zhong, L. Liu, S. Wikman, D. Cui, Z. Shen: Intragranular cellular segregation network structure strengthening $316 \mathrm{~L}$ stainless steel prepared by selective laser melting. Journal of Nuclear Materials, 470, 170-178, 2016. https://doi.org/10.1016/j.jnucmat.2015.12.034

[13] Y. Liu, Y. Yang, S. Mai, D. Wang, C. Song: Investigation into spatter behavior during selective laser melting of AISI 316L stainless steel powder. Materials \& Design, 87, 797-806, 2015. https://doi.org/10.1016/j.matdes.2015.08.086

[14] E. Brandl, U. Heckenberger, V. Holzinger, D. Buchbinder: Additive manufactured AlSi10Mg samples using Selective Laser Melting (SLM): microstructure, high cycle fatigue, and fracture behavior. Materials \& Design, 34, 159-169, 2012. https://doi.org/10.1016/j.matdes.2011.07.067

[15] C. Yan, L. Hao, A. Hussein, P. Young, J. Huang, W. Zhu: Microstructure and mechanical properties of aluminium alloy cellular lattice structures manufactured by direct metal laser sintering. Materials Science and Engineering: A, 628, 238-246, 2015. https://doi.org/10.1016/j.msea.2015.01.063

[16] C. Yan, L. Hao, A. Hussein, S. L. Bubb, P. Young, D. Raymont: Evaluation of lightweight Alsi10mg periodic cellular lattice structures fabricated via direct metal laser sintering. Journal of Materials Processing Technology, 214, 856-864, 2014. https://doi.org/10.1016/j.jmatprotec.2013.12.004

[17] S. Tsopanos, R. A. W. Mines, S. McKown, Y. Shen, W. J. Cantwell, W. Brooks, C. J. Sutcliffe: The Influence of Processing Parameters on the Mechanical Properties of Selectively Laser Melted Stainless Steel Microlattice Structures. Journal of Manufacturing Science and Engineering, 132, 041011:1041011:12, 2010.

[18] X. Wang, S. Xu, S. Zhou, W. Xu, M. Leary, P. Choong, M. Qian, M. Brandt, Y. M. Xie: Topological design and additive manufacturing of porous metals for bone scaffolds and orthopaedic implants: A review. Biomaterials, 83, 127-141, 2016. https://doi.org/10.1016/j.biomaterials.2016.01.012

[19] C. Yan, L. Hao, A. Hussein, P. Young: Ti-6Al-4V triply periodic minimal surface structures for bone implants fabricated via selective laser melting. Journal of the Mechanical Behavior of Biomedical Materials, 51, 61-73, 2015. https://doi.org/10.1016/j.jmbbm.2015.06.024

[20] C. Yan, L. Hao, A. Hussein, D. Raymont: Evaluations of cellular lattice structures manufactured using selective laser melting. International Journal of Machine Tools and Manufacture, 62, 32-38, 2012. https://doi.org/10.1016/j.ijmachtools.2012.06.002 
Mechanical Properties and Corrosion Behaviour of

316L Stainless Steel Honeycomb Cellular Cores

Manufactured by Selective Laser Melting
S.M. Zaharia, C. Lancea, L.A. Chicos, M.A. Pop, G. Caputo, E. Serra

[21] C. Yan, L. Hao, A. Hussein, P. Young, D. Raymont: Advanced lightweight 316 L stainless steel cellular lattice structures fabricated via selective laser melting. Materials \& Design, 55, 533-541, 2014. https://doi.org/10.1016/j.matdes.2013.10.027

[22] R. Gümrük, R. A. W. Mines, S. Karadeniz: Static mechanical behaviours of stainless steel micro-lattice structures under different loading conditions. Materials Science and Engineering: A, 586, 392-406, 2013. https://doi.org/10.1016/j.msea.2013.07.070

[23] R. Gümrük, R. A W. Mines: Compressive behaviour of stainless steel micro-lattice structures. International Journal of Mechanical Sciences, 68, 125-139, 2013. https://doi.org/10.1016/j.ijmecsci.2013.01.006

[24] M. Smith, Z. Guan, W. J. Cantwell: Finite element modelling of the compressive response of lattice structures manufactured using the selective laser melting technique. International Journal of Mechanical Sciences, 67, 28-41, 2013. https://doi.org/10.1016/j.ijmecsci.2012.12.004

[25] R. Mines, S. Tsopanos, Y. Shen, R. Hasan, S. McKown: Drop weight impact behaviour of sandwich panels with metallic micro lattice cores. International Journal of Impact Engineering, 60, 120-132, 2013. https://doi.org/10.1016/j.ijimpeng.2013.04.007

[26] A. Riemer, S. Leuders, M. Thöne, H.A. Richard, T. Tröster, T. Niendorf: On the fatigue crack growth behavior in 316L stainless steel manufactured by selective laser melting. Engineering Fracture Mechanics, 120, 15-25, 2014. https://doi.org/10.1016/j.engfracmech.2014.03.008

[27] K. Ushijima, W. J. Cantwell, R. A. W. Mines, S. Tsopanos, M. Smith: An investigation into the compressive properties of stainless steel micro-lattice structures. Journal of Sandwich Structures and Materials. 13, 303-329, 2011. https://doi.org/10.1177/1099636210380997

[28] K. Ushijima, W. J. Cantwell, D. H. Chen: Shear response of three-dimensional micro-lattice structures. Key Engineering Materials, 452-453, 713-716, 2010. https://doi.org/10.4028/www.scientific.net/KEM.452-453.713

[29] K. Ushijima, W. J. Cantwell, D. H. Chen: Prediction of the mechanical properties of micro-lattice structures subjected to multi-axial loading. International Journal of Mechanical Sciences, 68, 47-55, 2013. https://doi.org/10.1016/j.ijmecsci.2012.12.017

[30] S. McKown, Y. Shen, W. K. Brookes, C. J. Sutcliffe, W. J. Cantwell, G. S. Langdon, G. N. Nurick, M. D. Theobald: The quasi-static and blast loading response of lattice structures. International Journal of Impact Engineering, 35, 795-810, 2008. https://doi.org/10.1016/j.ijimpeng.2007.10.005

[31] B. Zhang, L. Dembinski, C. Coddet: The study of the laser parameters and environment variables effect on mechanical properties of high compact parts elaborated by selective laser melting 316L powder. Materials Science and Engineering: A, 584, 21-31, 2013. https://doi.org/10.1016/j.msea.2013.06.055

[32] G. R. Buican, G. Oancea, C. Lancea, M. A. Pop: Some considerations regarding microhardness of parts manufactured from 316-L steel using SLM technology. Applied Mechanics and Materials, 760, 515-520, 2015. https://doi.org/10.4028/www.scientific.net/AMM.760.515

[33] Y. Zhu, J. Zou, X. Chen, H. Yang: Tribology of selective laser melting processed parts: stainless steel 316L under lubricated conditions. Wear, 350-351, 46-55, 2016. https://doi.org/10.1016/j.wear.2016.01.004

[34] N. Dai, L. C. Zhang, J. Zhang, Q. Chen, M. Wu: Corrosion Behaviour of Selective Laser Melted Ti-6Al4V Alloy in NaCl Solution. Corrosion Science, 102, 484-489, 2016. https://doi.org/10.1016/j.corsci.2015.10.041

[35] H. Alsalla, L. Hao, C. Smith: Fracture toughness and tensile strength of 316 L stainless steel cellular lattice structures manufactured using the selective laser melting technique. Materials Science and Engineering: A, 669, 1-6, 2016. https://doi.org/10.1016/j.msea.2016.05.075

[36] K.G. Prashanth, L. Löber, H.-J. Klauss, U. Kühn, J. Eckert: Characterization of 316 L steel cellular dodecahedron structures produced by selective laser melting. Technologies, 4(4), 34, 2016. https://doi.org/10.3390/technologies4040034

[37] Q. Feng, Q. Tang, Z. Liu, Y. Liu, R. Setchi: An investigation of the mechanical properties of metallic lattice structures fabricated using selective laser melting. Proceedings of the Institution of Mechanical Engineers, Part B: Journal of Engineering Manufacture, First Published October 11, 2016. https://doi.org/10.1177/0954405416668924

[38] U. Martin, D. Ehinger, L. Kruger, S. Martin, T. Mottitschka, C. Weigelt, C.G. Aneziris, M. Herrmann: Cellular energy absorbing TRIP-Steel/Mg-PSZ composite: honeycomb structures fabricated by a new extrusion powder technology. Advances in Materials Science and Engineering, 2010, article ID 269537, 2010. https://doi.org/10.1155/2010/269537 
S.M. Zaharia, C. Lancea, L.A. Chicos, M.A. Pop, G. Caputo, E. Serra
Mechanical Properties and Corrosion Behaviour of 316L Stainless Steel Honeycomb Cellular Cores Manufactured by Selective Laser Melting

[39] S. M. Zaharia, I. Martinescu, C. O. Morariu: Life time prediction using accelerated test data of the specimens from mechanical element. Eksploatacja i Niezawodnosc-Maintenance and Reliability, 14, 2, 99-106, 2012.

[40] S. M. Zaharia, I. Martinescu: Management of accelerated reliability testing. Tehnički vjesnik, 23, 5, 1447-1455, 2016. https://doi.org/10.17559/TV-20141119153642

Submitted: $\quad 07.8 .2016$

Accepted: $\quad$ 12.6.2017
Sebastian Marian Zaharia $\triangle$

Camil Lancea

Lucia Antoneta Chicos

Department of Manufacturing Engineering Transilvania University of Brasov

Mihai Viteazu street, no. 5

Brasov, 500174, Romania

zaharia_sebastian@unitbv.ro

Mihai Alin Pop

Department of Materials Science

Transilvania University of Brasov

Colina Universitatii street., no. 1,

Brasov, 500068, Romania

Giampaolo Caputo

Emanuele Serra

Italian National Agency for New

Technologies, Energy and Sustainable

Economic Development - ENEA,

Casaccia Research Center,

Via Anguillarese no. 301,

Roma, 00123, Italy 